Bull. Mater. Sci, Vol. 17, No. 6, November 1994, pp. 1143-1153. (C) Printed in India.

\title{
Preparation, characterization and catalytic properties of the microporous titanosilicate, ETS-10
}

\author{
TAPAN Kr DAS, A J CHANDWADKAR and S SIVASANKER \\ Catalysis Division, National Chemical Laboratory, Pune 411 008, India

\begin{abstract}
ETS-10 is a novel large pore (12 membered ring) molecular sieve containing $\mathrm{Ti}^{4+}$ in $\mathrm{O}_{h}$ environment and $\mathrm{Si}^{4+}$ in $\mathrm{T}_{d}$ environment sharing common $\mathrm{O}^{2-}$ ions. As a result, ETS-10 possesses large ion-exchange and adsorption properties, besides being acidic in the H-form. We report our studies on its synthesis, characterization using SEM, IR, TGA/DTA, UV-VIS, MAS-NMR techniques, adsorption and catalytic properties.
\end{abstract}

Keywords. Titanosilicate; synthesis of ETS-10; characterization of ETS-10; catalytic properties of ETS-10.

\section{Introduction}

A new family of titanium silicate molecular sieves was recently discovered at Engelhard (Kuznicki 1990; Kuznicki et al 1991). These materials called ETS-4 and ETS-10 have unique molecular architecture due to octahedrally coordinated titanium framework ions. The structure of ETS-10 is an open three-dimensional one consisting of chains of $\mathrm{Ti}^{4+}$ octahedra linked to classical tetrahedral silica rings (Anderson $e t$ al 1994). A three-dimensional network of the interconnecting channels intersect a central pore $\left(8 \AA\right.$ diameter). ETS-10 has a significant ion exchange capacity $\left(2 \mathrm{Na}^{+}\right.$ or $2 \mathrm{~K}^{+}$per $\left.\mathrm{Ti}^{4+}\right)$ and the protonic form is moderately acidic.

In the present paper, we report our studies on the synthesis of ETS-10 using seeds of ETS-4, its characterization and catalytic properties in the dehydration of alcohols and isomerization of 1-butene and $m$-xylene.

\section{Experimental}

Synthesis of the titanosilicate (ETS-10) using seeds of ETS-4 was carried out hydrothermally using sodium silicate, titanium trichloride solution (15\% solution in $\mathrm{HCl}$, Loba Chemie, Bombay), sodium hydroxide, potassium fluoride dihydrate (GR Loba Chemie, Bombay) and seeds of ETS-4 (titanosilicate having small pore size $4 \AA$ A) prepared as reported earlier (Kuznicki et al 1991; Anderson et al 1994).

The molar composition of the gel in terms of oxides was as follows:

$$
\begin{aligned}
& 4.42 \mathrm{Na}_{2} \mathrm{O}: 0.95 \mathrm{~K}_{2} \mathrm{O}: \mathrm{TiO}_{2}: 5.71 \mathrm{SiO}_{2}: 81.88 \mathrm{H}_{2} \mathrm{O} \text { [ETS-4], } \\
& 3.70 \mathrm{Na}_{2} \mathrm{O}: 0.95 \mathrm{~K}_{2} \mathrm{O}: \mathrm{TiO}_{2}: 5.71 \mathrm{SiO}_{2}: 171 \mathrm{H}_{2} \mathrm{O} \text { [ETS-10]. }
\end{aligned}
$$

The synthesis of ETS-4 and ETS-10 were carried out as follows:

(i) Synthesis of ETS-4 (seed): A solution of sodium silicate was added to $\mathrm{NaOH}$ with stirring. Titanium trichloride $\left(\mathrm{TiCl}_{3} 15 \%\right.$ solution in $\mathrm{HCl}$ ) was added dropwise to the above mixture and stirred for $30 \mathrm{~min}$ to get a blackish paste. Potassium 
fluoride dihydrate $\left(\mathrm{KF} \cdot 2 \mathrm{H}_{2} \mathrm{O}\right)$ was next added to the mixture and stirred for $1 \mathrm{~h}$ at room temperature to get a homogeneous gel $(\mathrm{pH}=\sim 11.0$ ). This gel was transferred to a stainless steel autoclave and capped tightly and crystallization carried out at $423 \mathrm{~K}$ for 5-10 days. After crystallization the solid material was filtered off and washed with deionized water. The product was then dried and identified as the crystalline small pore titanosilicate (ETS-4) with the X-ray diffraction pattern presented in figure $1 \mathrm{~A}$.

(ii) Synthesis of ETS-10 using seeds of ETS-4: A solution of sodium silicate in distilled water was mixed with $\mathrm{NaOH}$ with stirring. Titanium trichloride $15 \%$ solution in $\mathrm{HCl}$ ) was then added dropwise to the above stirred gel. The paste like blackish material was allowed to stir for $30 \mathrm{~min}$. $\mathrm{KF} \cdot 2 \mathrm{H}_{2} \mathrm{O}$ was next added to the above paste and stirred well. Finally ETS-4 (seed, 6.99\%) was added and stirred vigorously for another $60 \mathrm{~min}$ till it was homogeneous $(\mathrm{pH}=10.8-11.0)$ at room temperature. The gel was transferred to a stainless steel autoclave and crystallized at $443 \mathrm{~K}$ for 10 days as mentioned above. The washed crystalline product was identified as the large pore titanosilicate (ETS-10) with the X-ray diffraction pattern presented in figure $1 \mathrm{~B}$.

The crystalline phase identification and phase purity of the sample was verified by X-ray diffraction (Rigaku, Model D-max III). The chemical composition of the samples was determined by a combination of wet chemical methods and atomic absorption spectroscopy (Hitachi Model Z-8000). Their average particle size and morphology were determined by scanning electron microscopy (JEOL, JSM 5200). The UV-VIS diffuse reflectance spectra of the samples were obtained by using a Shimadzu (Model UV-210PC) spectrometer. FTIR spectra were recorded with a Nicolet FTIR spectrometer (Model 60XB). The solid state MAS NMR ${ }^{29} \mathrm{Si}$ and ${ }^{23} \mathrm{Na}$ were recorded at $295 \mathrm{~K}$ using a Bruker MSL-300 FT NMR spectrometer. Bloch decays were averaged 2400 times before Fourier transformation to obtain

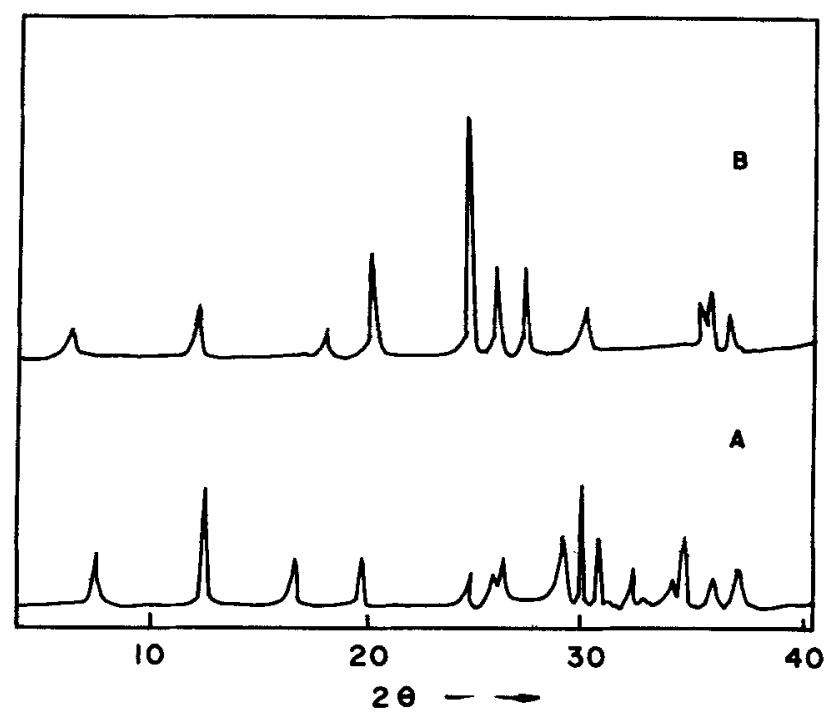

Figure 1. XRD patterns of the as-synthesized titanosilicates: (A) ETS-4 and (B) ETS-10. 
spectra with sufficient $\mathrm{S} / \mathrm{N}$. While acquiring ${ }^{29} \mathrm{Si}$ spectra, a recycle time of $4 \mathrm{~s}$ was found to be sufficient to give fully relaxed spectra. ${ }^{29} \mathrm{Si}$ spectra were measured using TMS as the primary reference. ${ }^{29} \mathrm{Si}$ NMR spectra were recorded at $\gamma=59.6$ MHz. An excitation pulse (t pulse) of $2 \mu$ s was used with $2000 \mathrm{NS}$ (no. of scans). While acquiring ${ }^{23} \mathrm{Na}$ spectra, a recycle time of $1 \mathrm{~s}$ was found to be sufficient to give fully relaxed spectra. ${ }^{23} \mathrm{Na}$ spectra were measured using sodium chloride as the primary reference. ${ }^{23} \mathrm{Na}$ spectra were recorded at $79.39 \mathrm{MHz}$. An excitation pulse of $2 \mu$ s was used with 200 NS.

The zeolite samples of different crystallinity were also further characterized by the adsorption of different probe molecules using a vacuum (Cahn) electrobalance. Prior to sorption measurements, about $200 \mathrm{mg}$ of the sample was activated at $\mathbf{5 7 3}$ $\mathrm{K}$ under vacuum. The ion-exchange property of the titanosilicate (ETS-10) was evaluated with $1.0 \mathrm{~N}(\mathrm{NaCl}+\mathrm{KCl})$ mixture and then ion exchanging further with 2-3 $\mathrm{N}$ ammonium nitrate solution. The exchange was done under reflux for $2 \mathrm{~h}$. The procedure was repeated to ensure complete ion-exchange.

The catalytically active protonic form of the titanosilicate [H-ETS-10] was obtained by repeated ion-exchange (till $\mathrm{Na}$ and $\mathrm{K}$ levels were less than 80 and $50 \mathrm{ppm}$ respectively in the solid) with $1 \mathrm{~N}$ solution of ammonium nitrate (wt of solution/wt of zeolite $=10$ ). The final product was filtered, dried (in an air oven at $383 \mathrm{~K}$ for $10 \mathrm{~h}$ ) and calcined stepwise at $623 \mathrm{~K}$ for $35-40 \mathrm{~h}$ in a flow of nitrogen and then air.

\section{Results and discussion}

\subsection{Synthesis of ETS-4 and ETS-10}

Chemical analysis of the synthesized samples are given below:

$$
\begin{aligned}
& 0.78 \mathrm{Na}_{2} \mathrm{O}: 0.28 \mathrm{~K}_{2} \mathrm{O}: \mathrm{TiO}_{2}: 3.11 \mathrm{SiO}_{2}: 3.18 \mathrm{H}_{2} \mathrm{O} \text { [ETS-4], } \\
& 0.82 \mathrm{Na}_{2} \mathrm{O}: 0.32 \mathrm{~K}_{2} \mathrm{O}: \mathrm{TiO}_{2}: 5.72 \mathrm{SiO}_{2}: 3 \cdot 11 \mathrm{H}_{2} \mathrm{O} \text { [ETS-10]. }
\end{aligned}
$$

The X-ray diffraction patterns of the titanosilicates ETS-4 and ETS-10 shown in figure 1 match very closely with those published earlier (Kuznicki 1990; Kuznicki et al 1991; Anderson et al 1994). The relative crystallinity of the sample was calculated by comparing the area of peak in the range of $2 \theta=24.65-27.5^{\circ}$ to that of the most crystalline reference materials (ETS-10) obtained from the same batch composition.

To study the effect of temperature on the formation of the titanosilicate, the kinetics of crystallization were studied in the range $423-473 \mathrm{~K}$ by comparing the extent of crystallization of the gel mixture at different intervals of synthesis time. The extent of crystallization was estimated from the ratios of the sum of the areas of the intense XRD peaks of the sample under consideration to that of the most crystalline sample obtained during the study (Domine and Quobex 1968; Tsitsishvilli et al 1979; Chao et al 1981). The curves (based on XRD estimation of crystallinity) for the crystallization kinetics of ETS-10 for the gel composition mentioned earlier are presented in figure 2. The curves typically exhibit a sharp continuous rise of crystallization. The intercept made by the curve on the time axis (abscissa) is defined as the induction period (the time needed to form crystallization centers or 
nuclei). In accordance with thermodynamic expectations, it is found from figure 2 that the induction period is inversely proportional to the temperature. The rate of nucleation may be assumed to be proportional to the reciprocal of the induction period and hence, it varies directly with the crystallization temperature. The induction period is followed by the rapid formation of crystalline material i.e. the rate of crystallization increases rapidly with time up to about $60-70 \%$ crystallinity and then slows down.

Linear plots were obtained when the data were fitted into Avrami-Erofeev equation (Kulkarni et al 1982). Applying the Arrhenius equation, the activation energy values for nucleation $\left(E_{n}\right)$ and crystallization $\left(E_{c}\right)$ were found. out to be 76.5 and $38.3 \mathrm{KJ} \mathrm{mol}^{-1}$, respectively. Recently shortcomings of the applicability of the above equation to zeolite crystallization data has been pointed out (Thompson 1992). He has proposed that these Avrami-Erofeev transformation kinetics should be viewed as providing only a qualitative interpretation of zeolite crystallizations. Therefore, no meaningful deductions should be drawn from these linear plots. The futility of the assumptions were explained (Den Ouden and Thompson 1992) to arrive at the rate of nucleation and crystal growth for the applicability of the Arrhenius equation to evaluate the apparent activation energies for the nucleation $\left(E_{n}\right)$ and crystal growth $\left(E_{c}\right)$ process.

\subsection{Characterization studies}

3.2a SEM analysis: SEM photographs show that the small pore titanosilicate (ETS-4) used as seed in the present study has very irregular undefined particles ranging in size from 1-8 $\mu \mathrm{m}$ (figure 3a). On the other hand, ETS-10 synthesized (with $\mathrm{H}_{2} \mathrm{O} / \mathrm{SiO}_{2}=30$ ) using ETS-4 seeds $\left(6.99 \mathrm{wt} \%\right.$ based on $\mathrm{SiO}_{2}$ input) crystallizes as sharp, twinned cuboids in the size range $1-4 \mu \mathrm{m}$ (figure $3 \mathrm{~b}$ ).

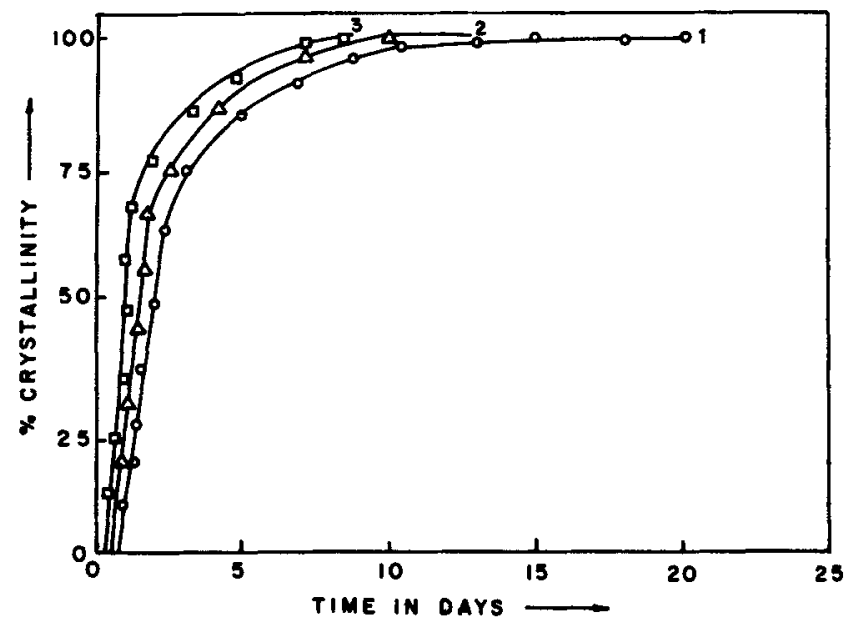

Figure 2. Effect of temperature on the kinetics of crystallization of ETS-10, Curves 1-3 correspond to $423 \mathrm{~K}, 443 \mathrm{~K}$ and $473 \mathrm{~K}$, respectively. 

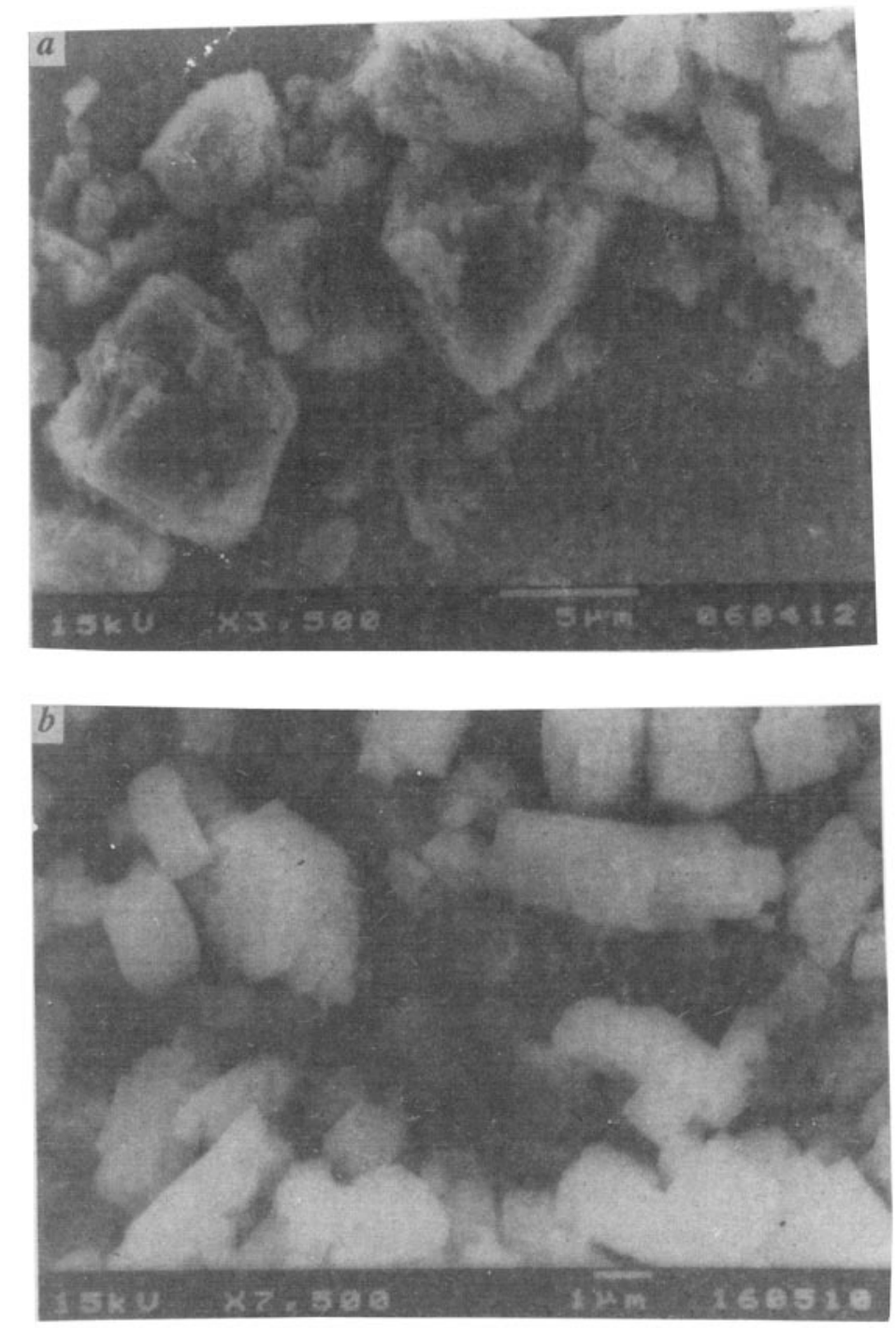

Figure 3. SEM photographs of titunosilicates: (a) ETS-4 (seed) and (b) ETS-10

$3.2 b$ IR studies: The framework IR spectra (in the region $450-1300 \mathrm{~cm}^{-1}$ ) of ETS-4 and ETS-10 are shown in figure 4 (curves A and B respectively). E'TS-4 shows a prominent band at $1000 \mathrm{~cm}^{-1}$ and two weak absorptions at 1100 and $920 \mathrm{~cm}^{-1}$. The positions of the major absorption bands and shoulders corresponding to the different symmetric and asymmetric stretching vibrations (Flanigen and Khatami 1971) remained almost unchanged $\left( \pm 5 \mathrm{~cm}^{-1}\right)$ for the titanosilicates prepared using seeds. The FTIR spectra of surface hydroxyl groups in dehydrated ETS-10 is shown in figure 5. The peak around $3735 \mathrm{~cm}^{-1}$ is due to isolated terminal silanol groups (Chandwadkar et al 1993). The sharp peak at $3700 \mathrm{~cm}^{-1}$ observed on ETS-10 


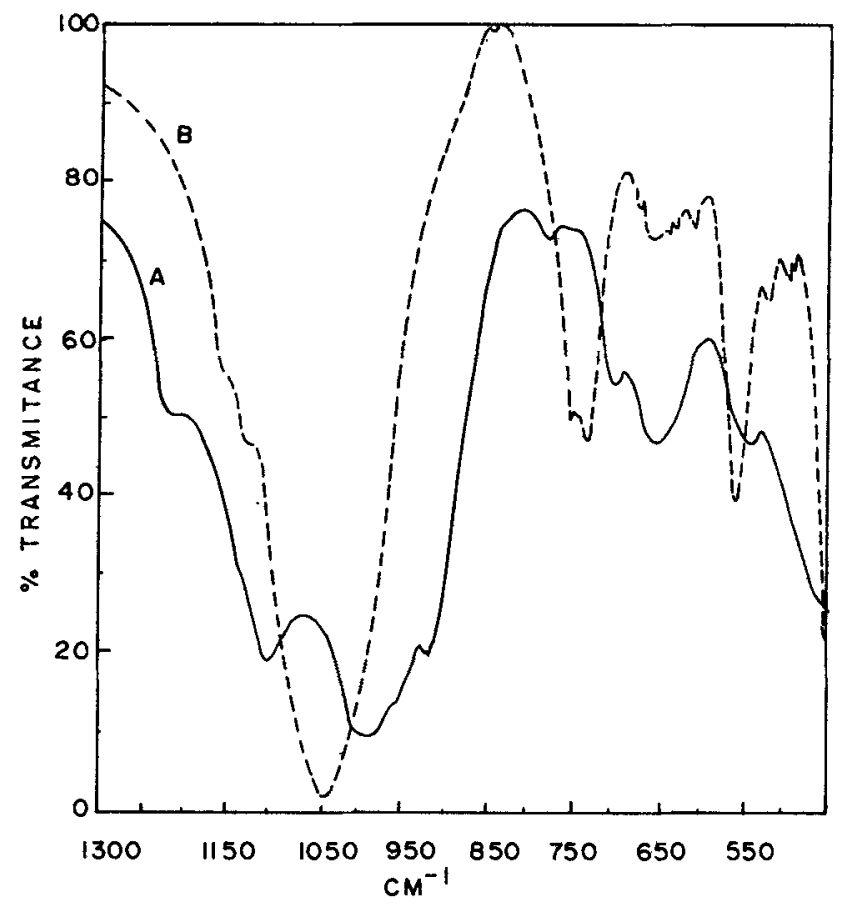

Figure 4. IR framework vibration spectra of the titanosilicates; (A) ETS-4 and (B) ETS-10.

probably is due to isolated $\mathrm{Ti}-\mathrm{OH}$ groups. The broad band around 3200$3600 \mathrm{~cm}^{-1}$ is probably due to $\mathrm{H}$-bonded surface hydroxyl groups of both $\mathrm{Si}$ and $\mathrm{Ti}$.

3.2c TGA/DTA: The thermal behaviour of ETS-10 is shown in figure 6 . The endotherm at $393 \mathrm{~K}$ is due to the loss of physically sorbed or occluded water, and at $\sim 963 \mathrm{~K}$ may be due to the dehydration of terminal $-\mathrm{OH}$ groups. The two exotherms with peak maxima at 573 and $723 \mathrm{~K}$ are probably due to phase transitions.

3.2d UV-VIS (DRS): The diffuse reflectance spectra in the UV-VIS region of ETS-10 and ETS-4 are presented in figure 7 (curves $a$ and $b$ respectively). The broad absorption in the region $250-320 \mathrm{~nm}$ suggest the presence of $\mathrm{Ti}^{4+}$ in $\mathrm{O}_{h}$ co-ordination (Jacobs 1992).

3.2e MAS-NMR: The ${ }^{29} \mathrm{Si}$ NMR spectrum of ETS-10 (figure 8A) shows three sharp bands at $\delta=-94.4(1),-96.8(2)$ and $-103.8(3) \mathrm{ppm}$, indicating the presence of at least three different $\mathrm{Si}$ environments in ETS-10. The weak band at $\delta=-90.74$ ppm (marked by an arrow) is probably due to ETS-4 present as an impurity in the sample as this band was prominent in the case of pure ETS-4. Further this band disappeared after calcination at $623 \mathrm{~K}$.

The ${ }^{23} \mathrm{Na}$ NMR spectrum (figure $8 \mathrm{~B}$ ) shows the presence of two resonance bands at $\delta=9 \cdot 17(1)$ and $-9.90(2) \mathrm{ppm}$ corresponding to their presence in two different environments (Engelhardt and Michel 1987). 


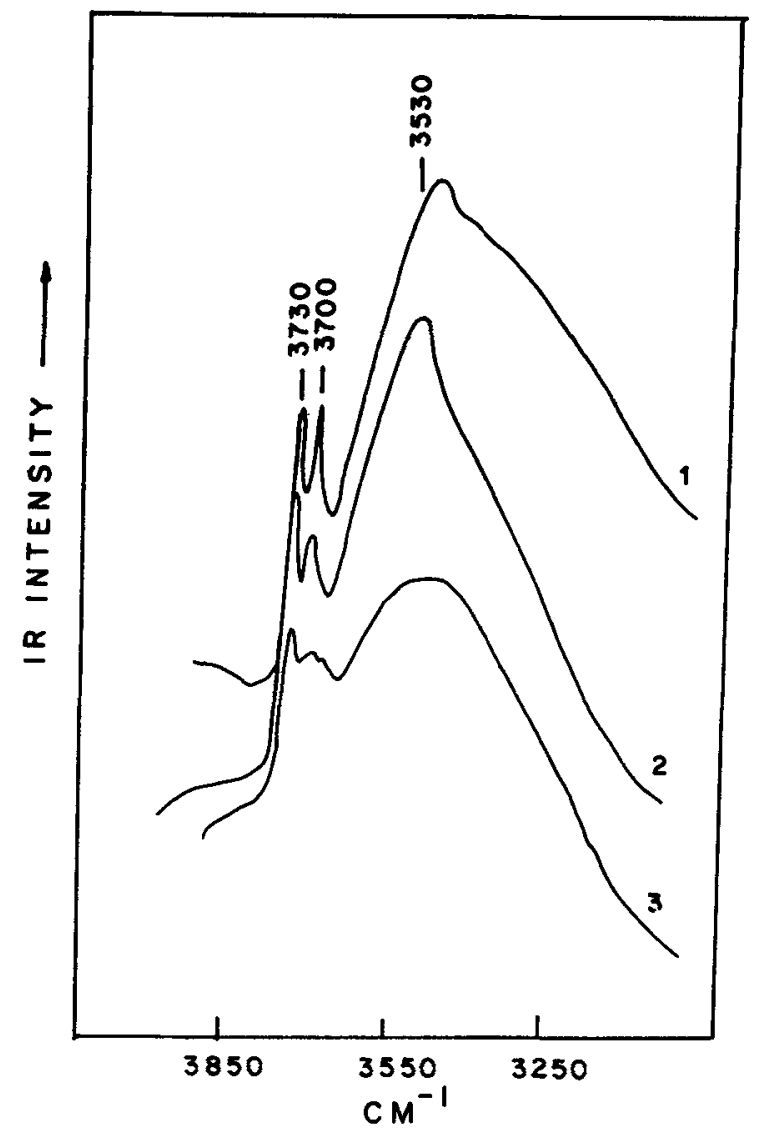

Figure 5. FTIR spectra of ETS-10 recoided at $313 \mathrm{~K}, 37.3 \mathrm{~K}$ and $473 \mathrm{~K}$ (curves $1-3$ respectively).

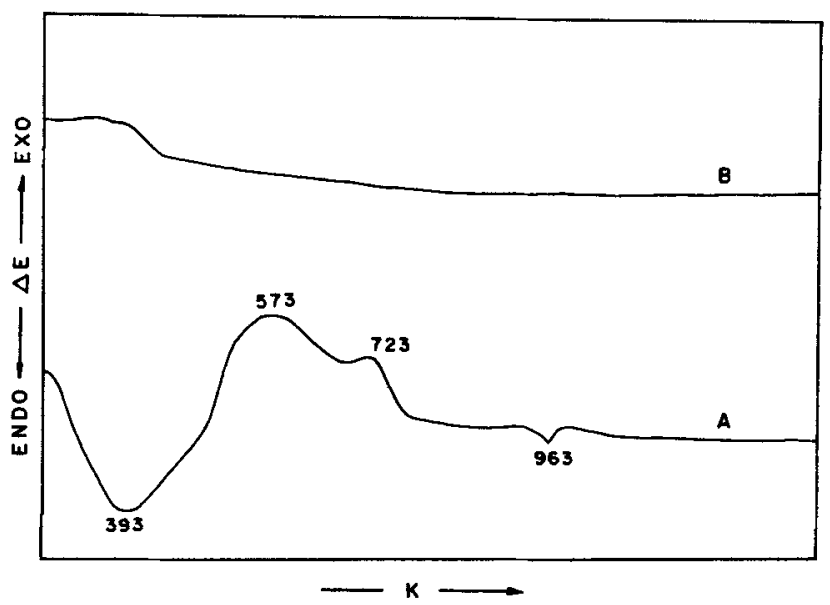

Figure 6. Thermoanalytical curves of ETS-10: (A) DTA and (B) TGA. 


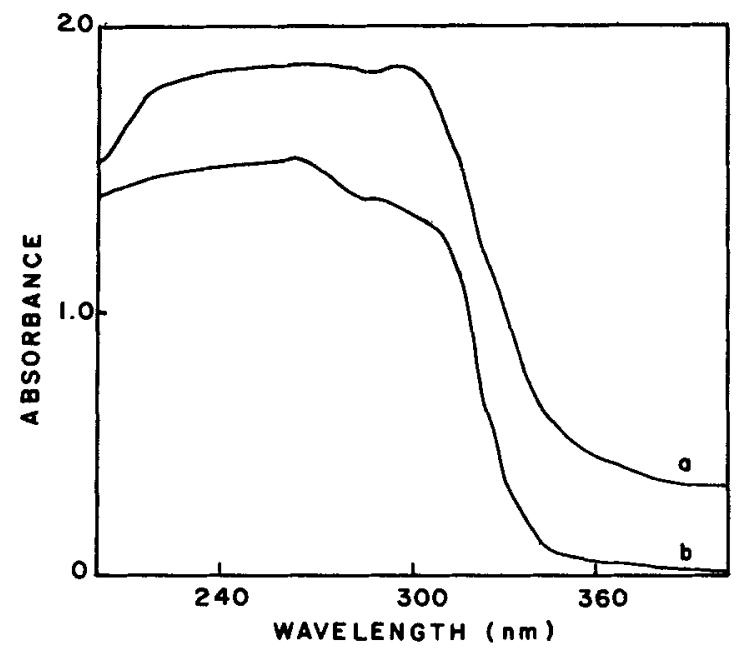

Figure 7. UV-VIS diffuse reflectance spectra of titanosilicate samples: (a) ETS-10 and (b) ETS-4.

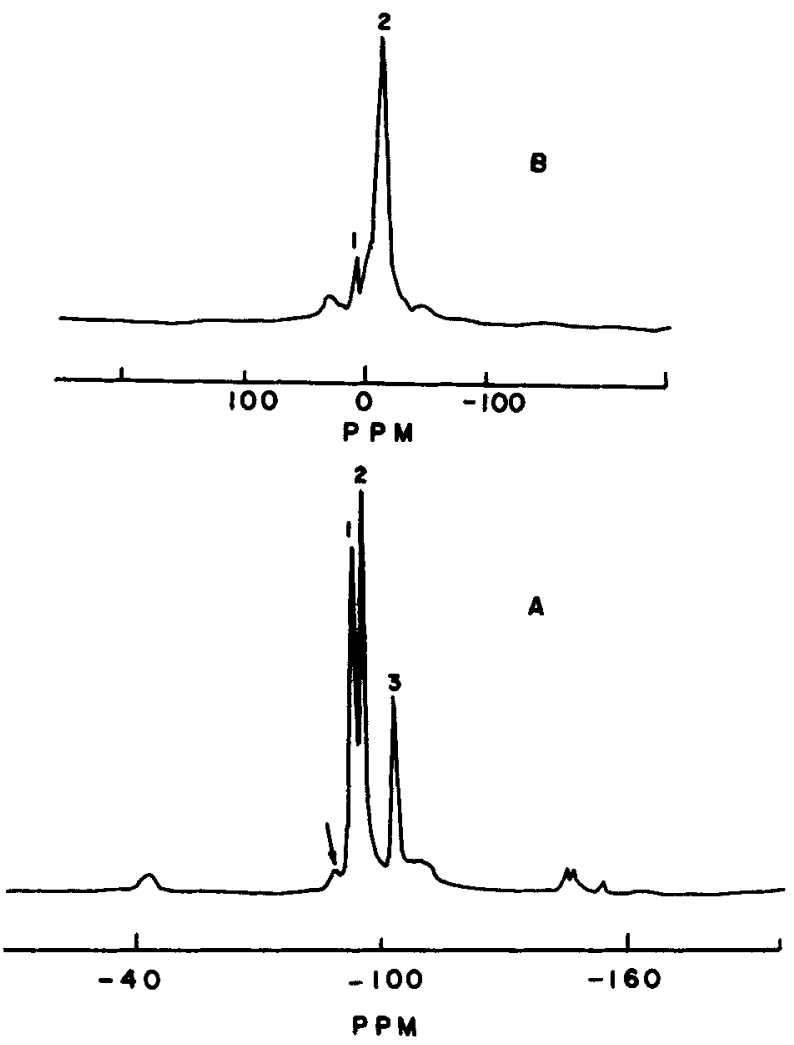

Figure 8. ${ }^{29} \mathrm{Si}$ and ${ }^{23} \mathrm{Na}$ MAS-NMR (curves A and B, respectively) of ETS-10. 
3.2f Sorption studies: The sorption isotherms for water, $n$-hexane and 1,3,5-trimethylbenzene obtained at $298 \mathrm{~K}$ at a $p / p_{0}=0.5$ are presented in figure 9. The large adsorption capacity for water shows that the molecular sieve is hydrophilic in nature. Besides, the rapid adsorption in large amounts of 1,3,5-trimethylbenzene (diameter $=8.4 \AA$ ) confirms that ETS-10 has pores of diameter of at least $8 \AA$.

\subsection{Catalytic studies}

3.3a Alcohol dehydration: H-ETS-10 is active in the dehydration of alcohols. In the case of dehydration of alcohols it decreases in the order: $t$-butanol > cyclohexanol $>$ isobutanol $>2$-butanol $>1$-butanol. The order of reactivities follows the same trend as the stabilities of the carbenium ions formed from them. The primary product of dehydration of isobutanol isomerizes further into 1- and 2-butenes. However, the isomerization is not significant when $t$-butanol is dehydrated. The dehydration of cyclohexanol leads mainly to cyclohexene and methyl-cyclopentenes $\left(\mathrm{MCP}^{-}\right)$, the latter products being formed by the skeletal rearrangement of cyclohexene (table 1).

3.3b Isomerization: ETS-10 isomerizes 1-butenes, with the formation of large quantities of saturated compounds (butanes 57\%). This shows that ETS-10 possess good hydrogen transfer activity. The excess hydrogen probably comes from the carbonaceous residues which were also formed in significant quantities.

The conversion of $m$-xylene over ETS-10 is moderate $(16.4 \%)$. The low I/D ratio (isomerization/disproportionation $\simeq 0.5$ ) shows that not only are the pores of ETS-10 large but also its acid site density is very high leading preferentially to bimolecular disproportionation reactions instead of isomerization reactions (table 2). High acid

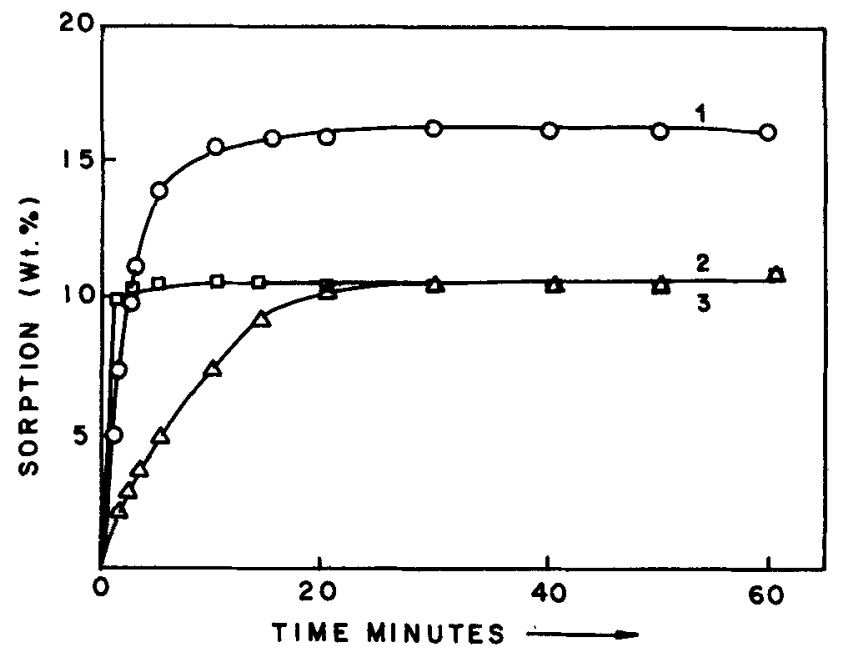

Figure 9. Sorption isotherms of $\mathrm{H}_{2} \mathrm{O}$, n-hexane and 1,3,5-trimethylbenzene (curves 1, 2 and 3 respectively) obtained over ETS- 10 . 
Table 1. Dehydration of alcohols over ETS-10.

\begin{tabular}{lccccc}
\hline & 1-butanol & 2-butanol & Isobutanol & t-butanol & Cycolhexanol \\
\cline { 2 - 6 } Conv. (\%) & 87.9 & 90.6 & 99.9 & 99.9 & 99.9 \\
\hline \multicolumn{7}{c}{ i-Butene } & 0.11 & 1.4 & 1.2 & 0.18 & - \\
Butene-1 & 17.2 & 7.2 & 10.4 & - & - \\
$i$-Butene & 2.5 & 48.0 & 54.5 & 98.8 & - \\
$n$-Butane & 0.5 & 0.24 & 0.22 & - & - \\
$t$-Butene-2 & 36.8 & 15.5 & 17.7 & 0.26 & \\
$c$-Butene-2 & 28.1 & 11.9 & 13.7 & 0.2 & - \\
Cyclohexene & - & - & - & - & 80.1 \\
MCP* & - & - & - & - & 18.4 \\
C -C 3 and & 2.7 & 6.4 & 2.1 & 0.5 & 0.9 \\
others & & & & & \\
\hline
\end{tabular}

Temp.: $573 \mathrm{~K}$, WHSV: $2\left(\mathrm{~h}^{-1}\right), \mathrm{N}_{2}:(5 \mathrm{ml} / \mathrm{min})$, Press.: 1 atm. TOS: $1 \mathrm{~h}$ *Methyl cyclopentenes.

Table 2. Isomerization activities of ETS-10.

\begin{tabular}{lclc}
\hline & 1-Butene & \multicolumn{2}{c}{$m$-Xylene } \\
\hline Conv. (\%) & 98.6 & Conv. (\%) & 16.4 \\
\hline & Products wt. (\%) & & Products wt. (\%) \\
\hline$C_{1}-C_{3}$ & 6.9 & Benzene & 1.9 \\
$i$-Butane & 43.5 & Toluene & 4.1 \\
$i$-Butene & 2.8 & $p$-Xylene & 1.0 \\
$n$-Butane & 13.3 & $o$-Xylene & 3.3 \\
$t$-Butane-2 & 2.6 & $1,3,5$ TMB* & 1.3 \\
$c$-Butane-2 & 1.8 & $1,2,4$ TMB* & 3.6 \\
$i$-Pentane & 18.7 & $1,2,3$ TMB* & 0.4 \\
Others & 9.0 & Others & 0.8 \\
\end{tabular}

Temp.: $573 \mathrm{~K}$, WHSV: $1\left(\mathrm{~h}^{-1}\right), \mathrm{N}_{2}:(5 \mathrm{ml} / \mathrm{min})$, Press.: $1 \mathrm{~atm}$. TOS: $1 \mathrm{~h}$

*Trimethylbenzenes.

site density is due to the fact that concentration of the $\mathrm{Ti}^{4+}$ ions is high and each $\mathrm{Ti}^{4+}$ ion can lead to two acid sites.

\section{Conclusions}

ETS- 10 can be suitably synthesized using ETS-4 as seeds. Infrared and UV-VIS(DRS) studies show that the $\mathrm{Ti}^{4+}$ ions are in $\mathrm{O}_{h}$ symmetries in ETS-10 as reported by earlier workers. Adsorption studies reveal that the molecular sieve is hydrophilic and has pores of diameter of at least $8 \AA$. ETS-10 is found to be active in the dehydration of alcohols and the isomerization of 1-butene and $m$-xylene.

\section{Acknowledgements}

We thank Dr P Ratnasamy for the helpful discussions, encouragement and support. TKD thanks CSIR, New Delhi for the Junior Research Fellowship. 


\section{References}

Anderson M W, Terasaki O, Ohsuna T, Phillippou T, Mackay S P, Ferreira A, Rochca J and Lidlin S 1994 Nature (London) 367347

Chandwadkar A J, Abdulla R A, Hegde S G and Nagy B 1993 Zeolites 13470

Chao K J, Tasi T C, Chen M S and Wang I 1981 J. Chem. Soc. Faraday. Trans. I, 77547

Den Ouden C J J and Thompson R W 1992 Ind. Eng. Chem. Res. 31369

Domine D and Quobex J 1968 Molecular sieves (London: Soc. Chem. Ind) p. 78

Engelhardt G and Michel D 1987 High resolution solid state NMR of silicates and zeolites (Chichester: John Wiley and Sons)

Flanigen E M and Khatami H $1971 \mathrm{Mol}$. Sieve Zeoliter I, Adv. Chem. Ser. 101201 (Washington D.C.: American Chemical Society)

Jacobs P A 1992 DGMK Tangenbericht 1719204

Kulkarni S B, Shiralkar V P, Kotasthane A N, Borade R B and Ratnasamy P 1982 Zeolites 2313

Kuznicki S M 1990 US Patent 4,938,939

Kuznicki S M, Madon R J, Koermer G S and Thrust K A 1991 European Patent 405978

Thompson R W 1992 Zeolites 12680

Tsitsishvilli G V, Krupenikov A Yu, Mamulashvili M V and Urushadze M V 1979 Russ. J. Phys. Chem. 53975 